\title{
Comparison of extracorporeal shock-wave therapy and wrist-extensor splint application in the treatment of lateral epicondylitis: a prospective randomized controlled study
}

This article was published in the following Dove Press journal: Journal of Pain Research

\author{
Abdulkadir Aydın' \\ Ramazan Atiç ${ }^{2}$ \\ 'Prosthetics and Orthotics \\ Department, Dicle University \\ Medical School, Diyarbakir, Turkey; \\ ${ }^{2}$ Orthopedics and Traumatology \\ Department, Dicle University Medical \\ School, Diyarbakır, Turkey
}

Background: Extracorporeal shock-wave therapy (ESWT) and wrist-extensor splints (WESs) are two commonly used methods in the treatment of lateral epicondylitis. In this study, the efficacy of these two methods was compared.

Methods: The study was planned as a prospective randomized controlled study. A total of 67 patients were enrolled. The patients were divided into two groups: group 1 received ESWT (32 patients) and group 2 received WES (35 patients). Patients in group 1 underwent four sessions of ESWT once every week. In each session, an ESWT device at 10-12 Hz, 2,000 pulses, and 1.6-1.8 bar pressure was used. Patients in group 2 used a wrist splint, holding the wrist at $30^{\circ}-45^{\circ}$ extension for 4 weeks. Patients were assessed for handgrip strength, pain at rest, pain while working, and quality of life. Data were collected before and after treatment (at weeks 4 , 12, and 24). A visual analog scale was used to evaluate pain at rest and while working, a hand dynamometer for handgrip strength, subscales of the SF36 Health Survey to evaluate quality of life, and the Turkish version of the patient-rated tennis-elbow evaluation was used to evaluate functioning of the affected arm during various daily life activities.

Results: In both ESWT and WES groups, although there were considerably significant improvements $(P<0.001)$ in the parameters evaluated (pain at rest and while working, handgrip strength, Patient-Rated Tennis Elbow Evaluation, Nirschl score, and SF36 subscales) were observed at 4, 12 , and 24 weeks compared to pretreatment values, there was no statistically significant difference between the two groups in terms of our evaluation parameters at the three time points $(P>0.05)$. Conclusion: Both ESWT and WES applications were found to yield significantly superior results when compared to pretreatment values. In comparison of the two groups, on the other hand, there was no statistically significant difference.

Keywords: Lateral epicondylitis, elbow pain, shockwave therapy, orthosis, quality of life

\section{Introduction}

Lateral epicondylitis (LE) is a common disease characterized by decreased grip and upper-extremity strength, along with pain on the outside of the elbow. It is pathology of the musculoskeletal system, secondary to recurrent microtrauma because of overuse of the upper extremity, causing pain and tenderness in the elbow area. ${ }^{1-3}$ It is also known as "tennis elbow", and is observed in 5\%-10\% of tennis players. ${ }^{4}$ The annual incidence in the population is $1 \%-3 \%,{ }^{5}$ with people aged $35-50$ years and older being most commonly affected. ${ }^{6,7}$ Clinically, it is characterized by pain radiating from the lateral aspect of the elbow to the forearm and loss of function because of decrease in
Correspondence: Abdulkadir Aydin Prosthetics and Orthotics Department, Dicle University Medical School, Kıtılbil Street, Sur/Diyarbakır 2I280, Turkey Tel +904I2248800I ext I44522 Email akcosut@dicle.edu.tr 
grip strength secondary to tenderness and pain at compression in the lateral epicondyle, and it is more frequently seen in the dominant hand..$^{5,8}$

Conservative approaches or surgical therapy can be used in the treatment of LE. The purpose of conservative treatment is to decrease pain, control inflammation, accelerate healing, and ensure that the patient performs daily life activities smoothly. While progressive strengthening is the most commonly used method among conservative treatment methods, other methods include watchful waiting, local injection, ultrasound, manipulation, manual therapy, Cyrax, lateral glide technique, extracorporeal shock-wave therapy (ESWT), laser, splinting, resting, hot-cold application, electrotherapy, massage, and oral or topical nonsteroidal anti-inflammatory drugs. ${ }^{9,10}$ Recently, ESWT has been used more commonly than other treatment methods, because it is noninvasive, well tolerated by patients, and has fewer side effects. ${ }^{11,12}$ However, the efficacy of ESWT in LE is controversial. Some studies have reported that ESWT is barely effective or as effective as placebo in LE. ${ }^{13,14}$ However, some other studies have reported that it is quite effective and could even be an alternative to surgery. ${ }^{15,16}$

Splinting, another conservative treatment method, is one of the most commonly used methods in LE, because it is noninvasive, painless, and easy to apply. Although splints are usually prescribed in LE, their efficacy remains controversial. ${ }^{17}$ In the chronic period of LE, most commonly forearm-counterforce braces and wrist-extensor splints (WESs) are used as proprioceptive input. ${ }^{8} \mathrm{~A}$ WES inhibits contraction of extensor muscles and thus muscle expansion in the proximal third of the forearm, decreases the movement of tendinous structures, and thus decreases stress at the common extensor origin. ${ }^{8,18}$ Although clinical examination is easily accepted by patients because of painless and easy diagnosis, conservative treatment is either not completed or delayed by patients, since treatment options take a long time and restrict daily life activities. In this study, we planned to evaluate clinical and demographic characteristics, pain, and quality of life in patients with LE receiving ESWT and WES and compare the data of two groups.

\section{Methods}

The was a planned prospective randomized controlled study, and conducted in accordance with the World Medical Association, Declaration of Helsinki, and the International Council for Harmonisation guidelines for good clinical practice. The study protocol was approved by the Dicle University Medical School ethics committee (DUTF-2013-79). In addition, participants were informed about the study. Written and verbal consent was received from all participants.
In the scope of the study, a total of 67 patients ( 33 females and 34 males) who had been treated based on a diagnosis of unilateral LE between September 2015 and May 2017 were evaluated. The mean age was $38.84 \pm 6.77$ years in the ESWT group and $37.94 \pm 6.45$ years in the WES group, and the mean body mass index was $27.21 \pm 1.38$ in the ESWT group and $26.340 \pm 2.29$ in the WES group. Figure 1 shows the schema for the patients' records.

The clinical diagnosis of LE was made with physical examination. In addition, standard anteroposterior and lateral elbow radiographs were obtained. Patients with pain in the lateral elbow, local tenderness to palpation on the lateral epicondyle, pain in the lateral elbow with resisted wrist extension, and patients with positive Mill's test ${ }^{19}$ results were included in the study. Patients with bilateral LE, carpal tunnel syndrome, cubital tunnel syndrome, previous elbow surgery, previous conservative and surgical treatment for LE, neurological deficits in the upper extremity, systemic disease, other diseases in the neck and shoulder region, lateral epicondylar tendon ruptures, tumors in the forearm and elbow, osteoporosis, and hemophilia were excluded from the study. All patients were instructed to avoid taking painkillers during the treatment and follow-up period. All patients were provided information on the procedures of the study.

\section{Study groups}

Patients receiving ESWT were designated as group 1 (32 patients) and those receiving WES as group 2 (35 patients). In the ESWT group (group $1-32 \mathrm{LE}$ ), four sessions of ESWT were delivered once per week. In each session, an ESWT device (DolorClast; EMS, Nyon, Switzerland) at 12 $\mathrm{Hz}, 2,000$ pulses, and 1.8 bar pressure was used. Shock waves can be focal or radial. Focal shock waves have deeper tissue penetration $(10 \mathrm{~cm})$ and a higher power effect $(0.08-0.28 \mathrm{~mJ} /$ $\mathrm{mm}^{2}$ ). Focal shock waves are not used for musculoskeletal disorders, because of their high energy and difficulty of application. Radial shock waves have lower penetration (3 $\mathrm{cm})$, lower effect $\left(0.02-0.06 \mathrm{~mJ} / \mathrm{mm}^{2}\right)$, and limited biological effect. ${ }^{20}$ Radial ESWT has been shown to be effective in more superficial musculoskeletal disorders, because of the limited amount of energy, simplicity of use, no need for sedation, and no need for monitoring with radiographic or echographic devices. ${ }^{21}$ Radial ESWT is commonly used in musculoskeletal diseases. The application was performed while the patient was in a sitting position with the shoulder at $45^{\circ}$ abduction, elbow flexed, and forearm supported in a supine position. ESWT was applied to the most tender spot on the lateral epicondyle and surrounding area. No 


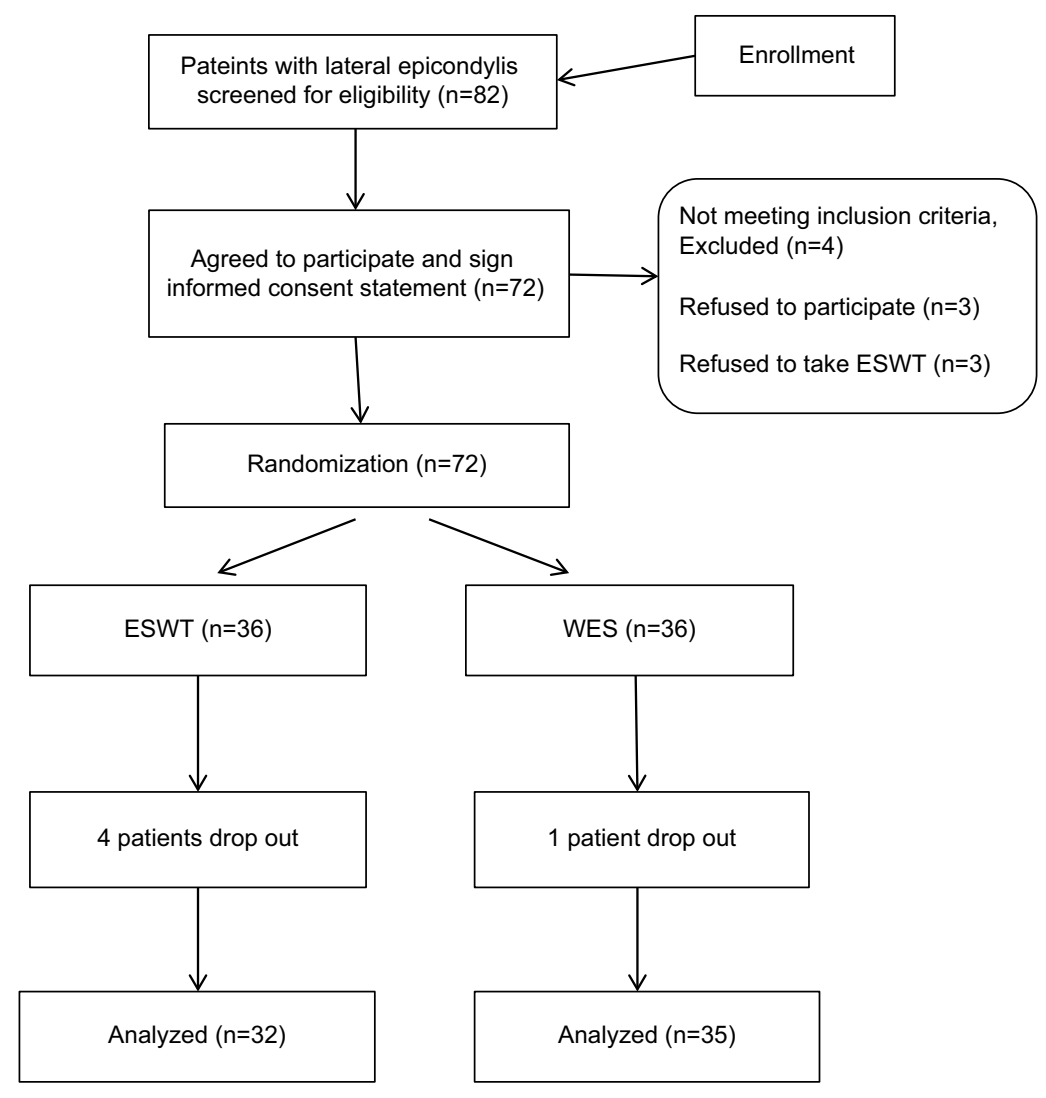

Figure I Flowchart for participants randomized to receive ESWT or WES.

Abbreviations: ESWT, extracorporeal shock-wave therapy; WES, wrist-extensor splint.

local anesthetic or analgesic medication was administered before or during application. In the WES group (group 2 - 35 LE), a wrist splint (Manu Comfort; Ottobock, Duderstadt, Germany) holding the wrist at $30^{\circ}-45^{\circ}$ extension was applied for 4 weeks. The patients were randomized using a numbered-envelope method. Both groups were given wristand forearm-strengthening isokinetic exercises.

\section{Measurement parameters}

Patients were evaluated for grip strength, pain at rest, pain while working, and quality of life. The same physiotherapist was blind to the randomization. Evaluation data were collected before and after treatment at weeks 4, 12, and 24 . A $10 \mathrm{~cm}$ visual analog scale (VAS) was used to evaluate pain at rest and while working ( 0 indicated no pain and 10 the worst pain). A Jamar hand dynamometer (Lafayette Instrument, Lafayette, IN, USA) was used to evaluate handgrip strength. The Jamar hydraulic hand dynamometer has the ability to measure grip strength via an analogue display in two separate units (pounds and kilograms) up to $200 \mathrm{lb}$ or $90 \mathrm{~kg}$. Five different positions can be set for people with different hand sizes. Three measure- ments were performed while the elbow was at $90^{\circ}$ flexion and the wrist in neutral position, and the average was recorded.

The SF36 Health Survey form was used to evaluate patients' quality of life. Koçyiğit et al evaluated the validity and reliability of the Turkish version of this questionnaire. ${ }^{22}$ The SF36 is composed of 36 items, and the scale contains eight subscales: physical functioning, physical role functioning, bodily pain, general health, vitality, social functioning, emotional role functioning, and mental health. Scores in each subscale range from 0 to 100 . Higher scores indicate better quality of life. ${ }^{23}$ The Turkish version of the Patient-Rated Tennis Elbow Evaluation (PRTEE-T) questionnaire was used to evaluate functioning of the affected arm during various daily life activities. The PRTEE-T questionnaire was validated by Altan et $\mathrm{al}^{48}$ in measuring changes in functional impairment. The PRTEE is composed of two subscales: pain (five questions); functional disability (ten questions), with functional disability composed of two subtitles - specific activities (six questions) and usual activities (four questions) - and 15 questions. In calculation, the average of the sum of specific activities and usual activities scales and the sum of pain scale 
are evaluated over 100. Low scores indicate that daily life activities are better. The questionnaire has considerably high reliability. ${ }^{24,25}$ We used Nirschl scores to assess pain in the affected arm during exercise. Patients were then instructed to mark the most appropriate option indicating the severity of pain during exercise on a Nirschl scale of 1-7 to evaluate pain in the affected arm during exercise. Low scores indicated lower intensity of pain during exercise in the affected arm. ${ }^{26}$ Three males and one female in the ESWT group and one male in the WES group failed to complete the treatment. These patients were excluded from the study.

\section{Statistical analysis}

In the statistical evaluation of our data, SPSS 15.0 for Windows program was used. Quantitative variables are presented as mean \pm SD and categorical variables as number and percentage. Data were tested for normal distribution. The independent $t$-test was used for paired comparisons of normally distributed variables of the ESWT and WES groups at 4, 12, and 24 weeks. Variables of the ESWT and WES groups without normal distribution at 4,12 , and 24 weeks were compared using the Mann-Whitney $U$ test. In comparison to the variables of the ESWT and WES groups at 4, 12, and 24 weeks, analysis of variance was used in repeated measurements. The $\chi^{2}$-test was used to compare qualitative variables of the groups. Hypotheses were two-tailed, and $P \leq 0.05$ was considered statistically significant. While the power analysis of the number of subjects we set for randomization was 0.82 for each group $(n=41)$, the power analysis of the number of subjects remaining after exclusion criteria was 0.76 for each group $(n=36)$. In addition, the power analysis of the total number of all subjects taken into the study $(n=67)$ was calculated to be 0.92 .

\section{Results}

Throughout the study period, no unfavorable condition was observed in the ESWT or WES groups. There was no statistically significant difference between the two groups in terms of demographic characteristics or evaluation parameters before treatment (Table 1). In terms of the occupation of the patients in the ESWT group, two were unemployed, nine were workers, 12 were office employees, two were retired, and seven were housewives. In the WES group, there were three unemployed, 10 workers, 13 office employees, one retired, and eight housewives. There was no significant difference between the two groups according to the occupational distribution of the patients $(P>0.05)$. There was no statistically significant difference in terms of disease duration either

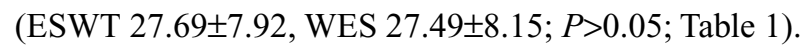

Mean VAS scores for pain at rest and pain while working before treatment in the ESWT group were $4.8 \pm 1.4$ and $7.2 \pm 2.6$, respectively, whereas mean VAS scores after treatment were $2.2 \pm 1.0$ and $3.2 \pm 1.7$ at 4 weeks $(54.17 \%$ and $55.6 \%$ reduction in pain), $1.9 \pm 0.9$ and $2.9 \pm 1.7$ at 12 weeks $(60.5 \%$ and $59.8 \%$ reduction in pain), and $2.4 \pm 1.1$ and $3.7 \pm 1.8$ at 24 weeks $(50.0 \%$ and $48.7 \%$ reduction in pain). There were statistically significant increases in grip strength at 4,12 , and 24 weeks after treatment compared to pretreatment values $(P<0.001)$. There were significant increases in PRTEE-T and Nirschl scores, which evaluated function and pain in the affected arm in various daily life activities at 4,12 , and 24 weeks compared to pretreatment values $(P<0.001)$. In addition, there were considerably significant improvements in all subscales of the SF36 (general health, physical functioning, physical role functioning, emotional role functioning, social functioning, bodily pain, mental health, and vitality) at 4,12 , and 24 weeks compared to pretreatment values $(P<0.001$; Table 2$)$.

Mean VAS scores for pain at rest and pain while working before treatment in the WES group were $4.7 \pm 1.5$ and $7.3 \pm 2.5$, respectively, whereas mean VAS scores after treatment were $2.1 \pm 1.1$ and $3.3 \pm 1.9$ at 4 weeks $(55.4 \%$ and $54.8 \%$ reduction in pain), $1.9 \pm 1.2$ and $3.1 \pm 1.8$ at 12 weeks $(59.6 \%$ and $57.6 \%$ reduction in pain), and $2.4 \pm 1.2$ and $3.4 \pm 1.9$ at 24 weeks $(49.0 \%$ and $53.5 \%$ reduction in pain). There were statistically significant increases in grip strength at 4,12 , and 24 weeks after treatment compared to pretreatment values $(P<0.001)$. There were significant increases in PRTEE-T and Nirschl scores evaluating functioning and pain of the affected arm in various daily life activities at 4,12 , and 24 weeks compared to pretreatment values $(P<0.001)$. In addition, there were significant improvements in all subscales of the SF36 at 4, 12, and 24 weeks compared to pretreatment values $(P<0.001$; Table 3$)$.

However, when results for WES patients in the ESWT and WES groups before treatment (at week 0 ) and after treatment (at weeks 4, 12, and 24) were compared, no statistically significant difference was found between the groups in terms of VAS scores for pain at rest, pain while working, grip strength, PRTEE-T and Nirschl scores evaluating functioning and pain of the affected arm in various daily life activities, or any subscale of the SF36 ( $P>0.05$; Table 4$)$.

\section{Discussion}

Several studies have evaluated the efficacy of ESWT and WESs. However, there has been no study evaluating the efficacy of these two methods comparatively. In our study, 
Table I Comparison of demographic characteristics between ESWT and WES groups

\begin{tabular}{llll}
\hline Demographic features & ESWT (n=32), mean \pm SD/n & WES (n=35), mean \pm SD/n & $P$ \\
\hline Age, years & $38.84 \pm 6.77(26 / 56)$ & $37.94 \pm 6.45(27 / 54)$ & $19 / 16(54.28 \% / 45.72 \%)$ \\
Sex, male/female & $15 / 17(46.87 \% / 53.13 \%)$ & $26.34 \pm 2.29(22.1 / 31.5)$ & 0.809 \\
BMI, kg/m & $27.21 \pm 1.38(24.5 / 30.1)$ & $30 / 5(85.71 \% / 14.29 \%)$ & 0.544 \\
Dominant hand right/left & $28 / 4(87.5 \% / 12.5 \%)$ & $27.49 \pm 8.15(14-44)$ & 0.830 \\
Disease duration (days) & $27.69 \pm 7.92(15-44)$ & $27 / 8(77.14 \% / 22.86 \%)$ & 0.778 \\
Side of involvement, right/left & $24 / 8(75 \% / 25 \%)$ & & 0.837 \\
Occupation & & $3(8.57 \%)$ & 0.436 \\
$\quad$ Unemployed & $2(6.25 \%)$ & $10(28.57 \%)$ & $13(37.14 \%)$ \\
Working & $9(28.12 \%)$ & $1(2.85 \%)$ & 0.886 \\
Officer & $12(37.50 \%)$ & $8(22.85 \%)$ & 0.812 \\
Retired & $2(6.25 \%)$ & 0.312 \\
Housewife & $7(21.87 \%)$ & 0.737 \\
\hline
\end{tabular}

Abbreviations: ESWT, extracorporeal shock-wave therapy; WES, wrist-extensor splint; BMI, body-mass index.

Table 2 Results and statistical comparisons of pretreatment (week 0) and posttreatment (after 4, I2, and 24 weeks) parameters in ESWT group $(n=32)$

\begin{tabular}{|c|c|c|c|c|c|c|c|}
\hline Elbow pain and QOL & $\begin{array}{l}\text { Baseline } \\
\text { (week 0) }\end{array}$ & $\begin{array}{l}\text { After } 4 \\
\text { weeks }\end{array}$ & $\begin{array}{l}\text { After I2 } \\
\text { weeks }\end{array}$ & $\begin{array}{l}\text { After } 24 \\
\text { weeks }\end{array}$ & $\begin{array}{l}P(\text { week 0- } \\
\text { week 4) }\end{array}$ & $\begin{array}{l}P(\text { week 0- } \\
\text { week I 2) }\end{array}$ & $\begin{array}{l}P(\text { week } 0- \\
\text { week 24) }\end{array}$ \\
\hline Pain at rest (VAS) & $4.8 \pm I .4$ & $2.2 \pm 1.0$ & $1.9 \pm 0.9$ & $2.4 \pm 1.1$ & $<0.001$ & $<0.001$ & $<0.001$ \\
\hline Pain under strain (VAS) & $7.2 \pm 2.6$ & $3.2 \pm 1.7$ & $2.9 \pm 1.7$ & $3.7 \pm 1.8$ & $<0.001$ & $<0.001$ & $<0.001$ \\
\hline Grip strength (kg) & $22.2 \pm 11.9$ & $26.1 \pm 12.8$ & $26.9 \pm 13.0$ & $24.9 \pm 12.1$ & $<0.001$ & $<0.001$ & $<0.001$ \\
\hline PRTEE-T & $60.5 \pm 22.3$ & $41.5 \pm 18.2$ & $39.3 \pm 18.1$ & $47.5 \pm 21.3$ & $<0.001$ & $<0.001$ & $<0.001$ \\
\hline Nirschl & $5.7 \pm 0.9$ & $3.1 \pm 0.7$ & $3.02 \pm 0.8$ & $3.7 \pm 0.8$ & $<0.001$ & $<0.00$ I & $<0.001$ \\
\hline \multicolumn{8}{|l|}{ SF36 } \\
\hline $\mathrm{GH}$ & $60.2 \pm 17.1$ & $74.8 \pm 21.0$ & $71.9 \pm 19.1$ & $68.9 \pm 18.2$ & $<0.001$ & $<0.001$ & $<0.001$ \\
\hline PF & $54.3 \pm 11.5$ & $70.9 \pm 13.8$ & $67.6 \pm 13.2$ & $64.6 \pm 12.0$ & $<0.001$ & $<0.001$ & $<0.001$ \\
\hline RLPR & $60.7 \pm 25.7$ & $71.0 \pm 27.2$ & $73.4 \pm 26.9$ & $69.1 \pm 26.5$ & $<0.001$ & $<0.001$ & $<0.001$ \\
\hline RLER & $59.3 \pm 19.7$ & $68.7 \pm 22.1$ & $71.8 \pm 23.0$ & $66.6 \pm 21.1$ & $<0.001$ & $<0.001$ & $<0.001$ \\
\hline SF & $59.7 \pm 16.6$ & $70.1 \pm 23.1$ & $72.5 \pm 23.3$ & $68.1 \pm 18.2$ & $<0.001$ & $<0.001$ & $<0.001$ \\
\hline $\mathrm{BP}$ & $54.7 \pm 13.4$ & $66.6 \pm 16.4$ & $67.0 \pm 16.7$ & $62.1 \pm 15.9$ & $<0.001$ & $<0.001$ & $<0.001$ \\
\hline $\mathrm{MH}$ & $55.0 \pm 18.1$ & $65.0 \pm 22.1$ & $64.5 \pm 21.9$ & $61.3 \pm 20.2$ & $<0.001$ & $<0.001$ & $<0.001$ \\
\hline$\vee$ & $51.8 \pm 14.3$ & $67.6 \pm 18.2$ & $68.9 \pm 14.4$ & $63.2 \pm 16.8$ & $<0.001$ & $<0.001$ & $<0.001$ \\
\hline
\end{tabular}

Abbreviations: ESWT, extracorporeal shock-wave therapy; VAS, visual analog scale; PRTEE-T, Patient-Rated Tennis Elbow Evaluation - Turkish; GH, general health; PF, physical functioning; RLPR, role limitation - physical reasons; RLER, role limitation - emotional reasons; SF, social function, BP, bodily pain; MH, mental health; $\mathrm{V}$, vitality; QOL, quality of life.

we compared the efficacy of these methods. There was no statistically significant difference between demographic and clinical characteristics of patient groups after randomization. The homogeneous distribution of the groups may indicate that results obtained after treatment were highly independent of pretreatment values.

In a systematic review, it was reported that LE was observed equally in males and females, but more frequently in male tennis players than female tennis players. ${ }^{27}$ In addition, according to the literature, LE is observed in the dominant hand more frequently. ${ }^{8}$ In our study, numbers of female and male patients were similar to each other (ESWT male/female
15/17, WES 19/16). In addition, similarly to Dundar et al, ${ }^{8}$ we found that LE was seen in the dominant hand more frequently (ESWT 24/8, WES 27/8). In the majority of studies on LE, VAS has been used to evaluate pain, and it has been stated that a 1-point change in VAS score might be of clinical significance. In some studies, on the other hand, a $50 \%$ reduction in VAS score from baseline was considered significant. ${ }^{28,29}$ In our study, we obtained 2.4-2.9 points of change in VAS scores compared to baseline values and reduction $>50 \%$ in both ESWT and WES groups. Measuring grip strength is an objective method of evaluating treatment response and functional recovery. ${ }^{30}$ In our study, we used a hand dynamometer 
Table 3 Results and statistical comparisons of pretreatment (week 0) and posttreatment (after 4, 12 and 24 weeks) evaluation parameters in WES group $(n=35)$

\begin{tabular}{|c|c|c|c|c|c|c|c|}
\hline Elbow pain and QOL & $\begin{array}{l}\text { Baseline } \\
\text { (week 0) }\end{array}$ & $\begin{array}{l}\text { After } \\
4 \text { weeks }\end{array}$ & $\begin{array}{l}\text { After } \\
12 \text { weeks }\end{array}$ & $\begin{array}{l}\text { After } \\
24 \text { weeks }\end{array}$ & $\begin{array}{l}P(\text { week 0- } \\
\text { week 4) }\end{array}$ & $\begin{array}{l}P(\text { week } 0- \\
\text { week I2) }\end{array}$ & $\begin{array}{l}P(\text { week } 0- \\
\text { week 24) }\end{array}$ \\
\hline Pain at rest (VAS) & $4.7 \pm 1.5$ & $2 . I \pm I . I$ & $1.9 \pm 1.2$ & $2.4 \pm 1.2$ & $<0.001$ & $<0.001$ & $<0.001$ \\
\hline Pain under strain (VAS) & $7.3 \pm 2.5$ & $3.3 \pm 1.9$ & $3.1 \pm 1.8$ & $3.4 \pm 1.9$ & $<0.001$ & $<0.001$ & $<0.001$ \\
\hline Grip strength (kg) & $22.1 \pm 9.2$ & $26.1 \pm 11.1$ & $26.5 \pm 11.7$ & $24.9 \pm 10.3$ & $<0.001$ & $<0.001$ & $<0.001$ \\
\hline PRTEE-T & $61.3 \pm 19.7$ & $43.3 \pm 13.1$ & $39.3 \pm 12.3$ & $46.1 \pm 13.9$ & $<0.001$ & $<0.001$ & $<0.001$ \\
\hline Nirschl & $5.8 \pm 1.3$ & $3.1 \pm 0.8$ & $3.1 \pm 0.9$ & $3.5 \pm 1.0$ & $<0.001$ & $<0.001$ & $<0.001$ \\
\hline \multicolumn{8}{|l|}{ SF36 } \\
\hline $\mathrm{GH}$ & $61.5 \pm 19.5$ & $76.4 \pm 26.4$ & $74.6 \pm 25.9$ & $71.5 \pm 23.3$ & $<0.001$ & $<0.001$ & $<0.001$ \\
\hline $\mathrm{PF}$ & $53.3 \pm 13.6$ & $69.2 \pm 18.1$ & $69.4 \pm 17.6$ & $64.5 \pm 16.3$ & $<0.001$ & $<0.001$ & $<0.001$ \\
\hline RLPR & $58.6 \pm 22.6$ & $71.4 \pm 27.2$ & $72.8 \pm 26.9$ & $67.8 \pm 25.7$ & $<0.001$ & $<0.001$ & $<0.001$ \\
\hline RLER & $60.9 \pm 22.4$ & $69.4 \pm 24.4$ & $72.3 \pm 24.9$ & $65.6 \pm 23.1$ & $<0.001$ & $<0.001$ & $<0.001$ \\
\hline SF & $58.9 \pm 27.7$ & $70.7 \pm 34.1$ & $73.9 \pm 33.7$ & $66.1 \pm 30.8$ & $<0.001$ & $<0.001$ & $<0.001$ \\
\hline BP & $53.7 \pm 14.2$ & $67.3 \pm 19.6$ & $67.7 \pm 20.1$ & $60.8 \pm 17.5$ & $<0.001$ & $<0.001$ & $<0.001$ \\
\hline $\mathrm{MH}$ & $53.6 \pm 14.9$ & $68.2 \pm 22.1$ & $67.1 \pm 21.3$ & $58.7 \pm 17.4$ & $<0.001$ & $<0.001$ & $<0.001$ \\
\hline
\end{tabular}

Abbreviations: WES, wrist-extensor splint; VAS, visual analog scale; PRTEE-T, Patient-Rated Tennis Elbow Evaluation - Turkish; GH, general health; PF, physical functioning; RLPR, role limitation - physical reasons; RLER, role limitation - emotional reasons; SF, social function, BP, bodily pain; MH, mental health; QOL, quality of life.

to evaluate grip strength. We noted significant improvement in both groups (ESWT, WES).

In many studies, the PRTEE scale was used to assess arm disability. ${ }^{31-33}$ PRTEE was shown to be an appropriate test in evaluating LE. In our study, we used the PRTEE-T. We obtained statistically significant results in PRTEE scores at 4, 12 , and 24 weeks compared to pretreatment values. Similarly, SF36 subscales have been used to evaluate quality of life in many studies. It has been emphasized that it is an important scale evaluating the quality of life. ${ }^{34-36}$ We also used SF36 subscales in our study. We obtained improvements in both ESWT and WES groups compared to pretreatment values. We planned a four-session treatment with a similar design to that of Pettrone et $\mathrm{al}^{37}$ with 2,000 pulses per session. Although application interval varies, in our study we applied ESWT with 7-day intervals, because generally accepted opinion for sufficient level of effectiveness is applying sessions with 5- to 7-day intervals. ${ }^{38}$

In the literature, there have been conflicting reports on the efficacy of ESWT in the treatment of LE. According to some publications, there is a reduction in pain and increase in functions and grip strength after ESWT application, 5,39,40 while according to some other studies, strong evidence was provided that ESWT has little or no benefit for lateral elbow pain. ${ }^{13,41-43}$ On the other hand, there have been studies advocating that ESWT is a treatment method yielding successful results, especially in persistent LE cases. ${ }^{44,45}$ The reason for these conflicting results might be differences in the number of pulses delivered, frequency, duration of application, treat- ment interval, and different devices used, depending on the different treatment protocols used. This is because when the literature is examined, it is seen that ESWT does not have a standard treatment protocol for LE, and different numbers of pulses, frequencies, duration of application, treatment intervals, and device applications are available.

There have been many studies comparing ESWT and different treatment methods in the treatment of LE. In a study in which ESWT and cryoultrasound were compared in a 1-year follow-up, Vulpiani et al obtained results in favor of ESWT at 6 months and at the end of 1 year in terms of VAS scores and patient satisfaction. ${ }^{38}$ Lee et al compared the efficacy of ESWT and corticosteroid injection in their study on patients with newly diagnosed LE and medial epicondylitis. ${ }^{46}$ They concluded that ESWT was as effective as injections after treatment and during the 8-week follow-up. Ozturan et al ${ }^{15}$ divided 60 patients with a complaint $>6$ months into three treatment groups and compared the effectiveness of corticosteroid injection, autologous blood, injection, and ESWT. In their study, while evaluating patients with the Thomsen test, upper-extremity function scores and grip strength during a 52-week follow-up were measured and found that the corticosteroid group was superior to the other groups at 4 weeks in terms of VAS and grip strength, but this superiority did not continue in the subsequent follow-ups. It was reported at 52 weeks of follow-up period that the corticosteroid injection had a success rate of $50 \%$, autologous blood injection had a success rate of $83 \%$, and ESWT had a success rate of $89 \%$. Radwan et al stated that ESWT could be an alterna- 


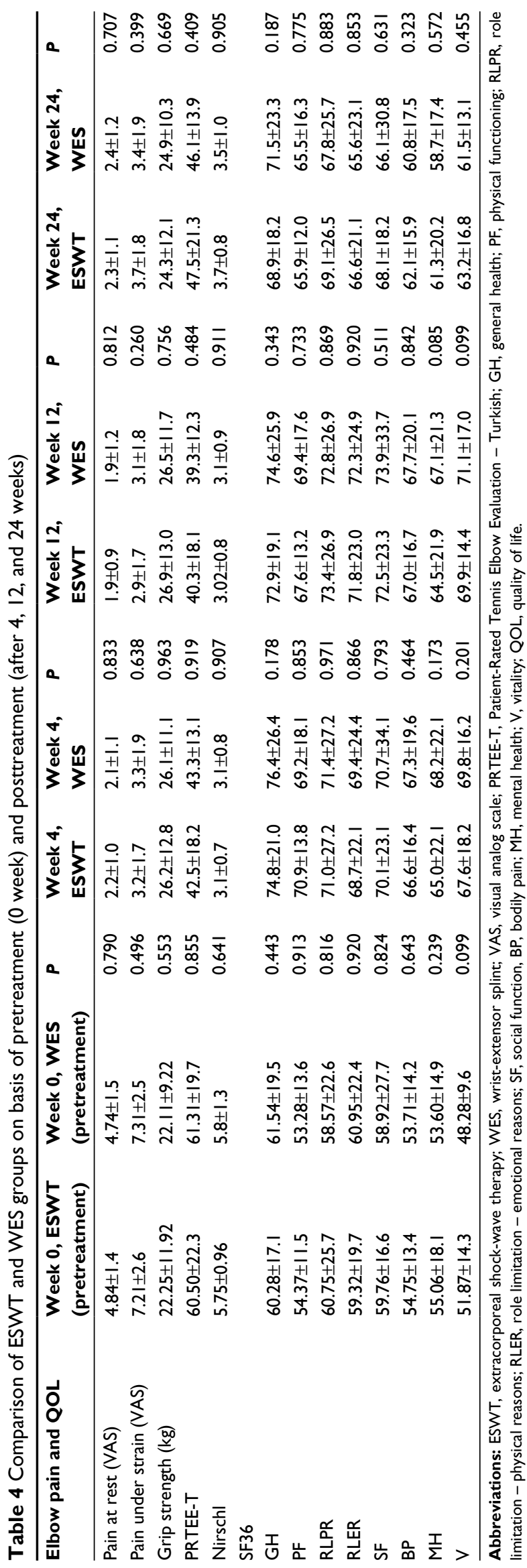

tive noninvasive treatment method to surgery. They reported that complications of ESWT were minor, it was easy to administer and noninvasive, yielded successful results close to surgery, and had a significant advantage in terms of costeffectiveness. ${ }^{16}$ However, no study was found in the literature comparing ESWT and splint application. In this sense, our study is an important work in this area.

When comparisons of ESWT with other physical therapy modalities were examined, ESWT was reported to be as effective as and even more effective than cryoultrasound, corticosteroid injection, autologous blood injection, massage, and laser applications, and that it could be an alternative to surgery. In our study, we also found that ESWT is as effective as WES.

Splinting is one of the conservative methods commonly used in the treatment of LE. The most commonly used orthoses are forearm-counterforce braces, resting hand-wrist splints, and WESs, which allow the muscle to rest in the acute phase and provide proprioceptive input in the chronic phase. ${ }^{8}$ Splints can make daily life activities easier, decrease pain, and increase grip strength, and they are affordable. However, there have been no definite conclusions reported on the effectiveness of orthoses in the treatment of LE, because of variability in control groups, outcome measures, type of splint used, duration of complaints, prognostic factors, and low number of patients. ${ }^{47}$ In a study conducted by Altan et al, ${ }^{48}$ a reduction in pain was detected with the use of an LE band and a wrist-resting splint, which held the wrist slightly dorsiflexed, in patients with LE $<3$ months. However, there was no significant difference between the two splints in terms of effectiveness in the long term. Similarly to Altan et al, we also used a splint in our study, which held the wrist in extension (dorsiflexion). We achieved significant pain relief and improvement in grip strength and quality of life. In general terms, although there have been studies reporting that splinting in LE was effective in decreasing pain and improving grip strength, ${ }^{8,47-49}$ in a retrospective cohort study conducted by Derebery et al, ${ }^{50}$ it was reported that patients with LE who were followed with splinting had higher revisit rates and longer treatment duration compared with patients who were treated without splinting. It was stated that early mobilization might be more effective than resting and immobilization provided by bandage might delay healing. In a systematic review of studies that compared splinting with conservative therapies, no difference was found between splinting, physiotherapy, or topical nonsteroidal anti-inflammatory drugs, whereas in one study corticosteroid injection was found to be superior 
in the early period. ${ }^{47}$ In our study, we found that WES was as effective as ESWT in decreasing pain, increasing grip strength, and improving quality of life.

Presently, there is no universally accepted and standardized LE-treatment program. For this reason, we examined the effectiveness of ESWT and WESs both in themselves and in comparison with each other. Both treatment methods were noninvasive, painless, and easy to apply. In conclusion, we found that ESWT and WES were considerably effective in decreasing pain, improving grip strength, increasing quality of life, and alleviating arm pain during daily life activities in the treatment of LE. It can be said that ESWT and WES are effective conservative treatment options in the treatment of LE. As both methods are comparable in terms of efficacy, when we evaluate ESWT and WES in terms of cost-effectiveness and efficacy, WES seems to be slightly more advantageous than ESWT, because WES is cheap, easy to apply, and does not cause complications. We recommend the use of WES in terms of cost-effectiveness and efficacy. Our study has some limitations. The SF36, PRTEE, and Nirschl questionnaires are patient-reported instruments, and the number of patients in the study was low.

\section{Disclosure}

The authors report no conflicts of interest in this work.

\section{References}

1. Nirschl RP, Pettrone FA. Tennis elbow: the surgical treatment of lateral epicondylitis. J Bone Joint Surg Am. 1979;61(6A):832-839.

2. Morrey BF, editor. Limited and extensile triceps reflecting exposures of the elbow. In: Master Techniques in Orthopaedic Surgery: The Elbow. New York: Raven Press; 1994:3-20.

3. Barrington J, Hage WD, Epicondylitis L. Lateral epicondylitis (tennis elbow): nonoperative, open, or arthroscopic treatment? Curr Opin Orthop. 2003;14(4):291-295.

4. Kane SF, Lynch JH, Taylor JC. Evaluation of elbow pain in adults. Am Fam Physician. 2014;89(8):649-657.

5. Trentini R, Mangano T, Repetto I, et al. Short- to mid-term follow-up effectiveness of US-guided focal extracorporeal shock wave therapy in the treatment of elbow lateral epicondylitis. Musculoskelet Surg. 2015;99(Suppl 1):S91-S97.

6. Johnson GW, Cadwallader K, Scheffel SB, Epperly TD. Treatment of lateral epicondylitis. Am Fam Physician. 2007;76(6):843-848.

7. Gündüz R, Malas FU, Borman P, Kocaoğlu S, Ozçakar L. Physical therapy, corticosteroid injection, and extracorporeal shock wave treatment in lateral epicondylitis: clinical and ultrasonographical comparison. Clin Rheumatol. 2012;31(5):807-812.

8. Dundar U, Turkmen U, Toktas H, Ulasli AM, Solak O. Effectiveness of high-intensity laser therapy and splinting in lateral epicondylitis: a prospective, randomized, controlled study. Lasers Med Sci. 2015;30(3):1097-1107.

9. Luk JK, Tsang RC, Leung HB. Lateral epicondylalgia: midlife crisis of a tendon. Hong Kong Med J. 2014;20(2):145-151.
10. Ahmad Z, Siddiqui N, Malik SS, Abdus-Samee M, Tytherleigh-Strong $\mathrm{G}$, Rushton N. Lateral epicondylitis: a review of pathology and management. Bone Joint J. 2013;95-B(9):1158-1164.

11. Yang TH, Huang YC, Lau YC, Wang LY. Efficacy of radial extracorporeal shock wave therapy on lateral epicondylosis and changes in the common extensor tendon stiffness with pretherapy and posttherapy in real-time sonoelastography. Am J Phys Med Rehabil. 2017;96(2):93-100.

12. Wong CW, Ng EY, Fung PW, Mok KM, Yung PS, Chan KM. Comparison of treatment effects on lateral epicondylitis between acupuncture and extracorporeal shockwave therapy. Asia Pac J Sports Med Arthrosc Rehabil Technol. 2017;7:21-26.

13. Beyazal MS, Devrimsel G. Comparison of the effectiveness of local corticosteroid injection and extracorporeal shock wave therapy in patients with lateral epicondylitis. J Phys Ther Sci. 2015;27(12):3755-3758.

14. Buchbinder R, Green SE, Youd JM, Assendelft WJ, Barnsley L, Smidt N. Systematic review of the efficacy and safety of shock wave therapy for lateral elbow pain. $J$ Rheumatol. 2006;33(7):1351-1363.

15. Ozturan KE, Yucel I, Cakici H, Guven M, Sungur I. Autologous blood and corticosteroid injection and extracorporeal shock wave therapy in the treatment of lateral epicondylitis. Orthopedics. 2010;33(2):84-91.

16. Radwan YA, Elsobhi G, Badawy WS, Reda A, Khalid S. Resistant tennis elbow: shock-wave therapy versus percutaneous tenotomy. Int Orthop. 2008;32(5):671-677.

17. Garg R, Adamson GJ, Dawson PA, Shankwiler JA, Pink MM. A prospective randomized study comparing a forearm strap brace versus a wrist splint for the treatment of lateral epicondylitis. J Shoulder Elbow Surg. 2010;19(4):508-512.

18. Struijs PA, Kerkhoffs GM, Assendelft WJ, van Dijk CN. Conservative treatment of lateral epicondylitis: brace versus physical therapy or a combination of both: a randomized clinical trial. Am J Sports Med. 2004;32(2):462-469.

19. Bhargava AS, Eapen C, Kumar SP. Grip strength measurements at two different wrist extension positions in chronic lateral epicondylitiscomparison of involved vs. uninvolved side in athletes and non athletes: a case-control study. Sports Med Arthrosc Rehabil Ther Technol. 2010;2:22.

20. Greve JM, Grecco MV, Santos-Silva PR. Comparison of radial shockwaves and conventional physiotherapy for treating plantar fasciitis. Clinics (Sao Paulo). 2009;64(2):97-103.

21. Mangone G, Veliaj A, Postiglione M, Viliani T, Pasquetti P. Radial extracorporeal shock-wave therapy in rotator cuff calcific tendinosis. Clin Cases Miner Bone Metab. 2010;7(2):91-96.

22. Koçyiğit H, Aydmir O, Fişek G, Olmez N, Memiş A. Kısa form-36 (KF-36)'nın Türkçe versiyonunun güvenilirliği ve geçerliliği: romatizmal hastalığı olan bir grup hasta ile çalışma. Ilac Tedavi Derg. 1999;12(1):102-106.

23. Wang G, Gao Q, Hou J, Li J. Effects of temperature on chronic trapezius myofascial pain syndrome during dry needling therapy. Evid Based Complement Alternat Med. 2014;2014:638268.

24. Capan N, Esmaeilzadeh S, Oral A, Basoglu C, Karan A, Sindel D. Radial extracorporeal shock wave therapy is not more effective than placebo in the management of lateral epicondylitis: a double-blind, randomized, placebo- controlled trial. Am J Phys Med Rehabil. 2016;95(7):495-506.

25. Cacchio A, Necozione S, Macdermid JC, et al. Cross-cultural adaptation and measurement properties of the Italian version of the PatientRated Tennis Elbow Evaluation (PRTEE) questionnaire. Phys Ther. 2012;92(8):1036-1045.

26. Nirschl RP, Ashman ES. Tennis elbow tendinosis (epicondylitis). Instr Course Lect. 2004;53:587-598.

27. Aam BS, Nejad L. Systematic review: effects of using Kinesio tape on treatment of lateral epicondylitis. Phys Treat. 2014;4(3):115-122.

28. Rompe JD, Decking J, Schoellner C, Theis C. Repetitive low-energy shock wave treatment for chronic lateral epicondylitis in tennis players. Am J Sports Med. 2004;32(3):734-743. 
29. Speed CA, Nichols D, Richards C, et al. Extracorporeal shock wave therapy for lateral epicondylitis: a double blind randomised controlled trial. J Orthop Res. 2002;20(5):895-898.

30. Benson EC, Athwal GS, King GJ. Clinical assessment of the elbow. In: Trail SD, editor. Operative Elbow Surgery. London: Churchill Livingstone; 2012:45-65.

31. Alessio-Mazzola M, Repetto I, Biti B, Trentini R, Formica M, Felli L. Autologous US-guided PRP injection versus US-guided focal extracorporeal shock wave therapy for chronic lateral epicondylitis: a minimum of 2-year follow-up retrospective comparative study. J Orthop Surg (Hong Kong). 2018;26(1):230949901774998.

32. Gaspar MP, Motto MA, Lewis S. Platelet-rich plasma injection with percutaneous needling for recalcitrant lateral epicondylitis. Orthop $J$ Sports Med. 2017;5(12):2325967117742077.

33. Uygure E, Aktaş B, Ozkut A, Erinç S, Yılmazoglu EG. Dry needling in lateral epicondylitis: a prospective controlled study. Int Orthop. 2017;41(11):2321-2325.

34. Nascimento AT, Claudio GK. Arthroscopic surgical treatment of recalcitrant lateral epicondylitis: series of 47 cases. Rev Bras Ortop. 2017;52(1):46-51.

35. Kaux JF, Delvaux F, Schaus J, et al. Cross-cultural adaptation and validation of the Patient-Rated Tennis Elbow Evaluation Questionnaire on lateral elbow tendinopathy for French-speaking patients. J Hand Ther. 2016;29(4):496-504.

36. Akkurt E, Kucuksen S, Yılmaz H, Parlak S, Sallı A, Karaca G. Long term effects of high intensity laser therapy in lateral epicondylitis patients. Lasers Med Sci. 2016;31(2):249-253.

37. Pettrone FA, Mccall BR. Extracorporeal shock wave therapy without local anesthesia for chronic lateral epicondylitis. J Bone Joint Surg Am. 2005;87(6):1297-1304.

38. Vulpiani MC, Nusca SM, Vetrano M. Extracorporeal shock wave therapy vs cryoultrasound therapy in the treatment of chronic lateral epicondylitis: one year follow up study. Muscles Ligaments Tendons J. 2015;20;5(3):167-174.
39. Spacca G, Necozione S, Cacchio A. Radial shock wave therapy for lateral epicondylitis: a prospective randomised controlled single-blind study. Eura Medicophys. 2005;41(1):17-25.

40. Wang CJ, Chen HS. Shock wave therapy for patients with lateral epicondylitis of the elbow: a one-to two-year follow-up study. Am J Sports Med. 2002;30(3):422-425.

41. Melikyan EY, Shahin E, Miles J, Bainbridge LC. Extracorporeal shockwave treatment for tennis elbow. J Bone Joint Surg Br. 2003;85(6):852-855.

42. Weber C, Thai V, Neuheuser K, Groover K, Christ O. Efficacy of physical therapy for the treatment of lateral epicondylitis: a meta-analysis. BMC Musculoskelet Disord. 2015;16:223.

43. Haake M, König IR, Decker T, et al. Extracorporeal shock wave therapy in the treatment of lateral epicondylitis: a randomized multicenter trial. J Bone Joint Surg Am. 2002;84(11):1982-1991.

44. Thiele S, Thiele R, Gerdesmeyer L. Lateral epicondylitis: this is still a main indication for extracorporeal shockwave therapy. Int J Surg. 2015;24(Pt B):165-170.

45. Dion S, Wong JJ, Côté $\mathrm{P}$, et al. Are passive physical modalities effective for the management of common soft tissue injuries of the elbow? A systematic review by the Ontario Protocol for Traffic Injury Management (OPTIMa) Collaboration. Clin J Pain. 2017;33(1):71-86.

46. Lee SS, Kang S, Park NK, et al. Effectiveness of initial extracorporeal shock wave therapy on the newly diagnosed lateral or medial epicondylitis. Ann Rehabil Med. 2012;36(5):681-687.

47. Struijs PA, Smidt N, Arola H, et al. Orthotic devices for the treatment of tennis elbow. Cochrane Database Syst Rev. 2002;1:CD001821.

48. Altan L, Kanat E. Conservative treatment of lateral epicondylitis: comparison of two different orthotic devices. Clin Rheumatol. 2008;27(8):1015-1019.

49. Borkholder CD, Hill VA, Fess EE. The efficacy of splinting for lateral epicondylitis: a systematic review. J Hand Ther. 2004;17(2):181-199.

50. Derebery VJ, Devenport JN, Giang GM, Fogarty WT. The effects of splinting on outcomes for epicondylitis. Arch Phys Med Rehabil. 2005;86(6):1081-1088.
Journal of Pain Research

\section{Publish your work in this journal}

The Journal of Pain Research is an international, peer reviewed, open access, online journal that welcomes laboratory and clinical findings in the fields of pain research and the prevention and management of pain. Original research, reviews, symposium reports, hypothesis formation and commentaries are all considered for publication.

\section{Dovepress}

The manuscript management system is completely online and includes a very quick and fair peer-review system, which is all easy to use. Visit http://www.dovepress.com/testimonials.php to read real quotes from published authors. 